\title{
Effect of a transient, geographically localised economic recovery on community health and income studied with longitudinal household cohort interview method
}

\author{
L Lee Glenn, Rubye W Beck, Gary L Burkett
}

\begin{abstract}
Study objective-The main purpose of the study was to determine whether the health or economic status of a cohort of residents in an economically troubled geographical area changed between 1990 and 1993.

Design-Longitudinal, single cohort, interview survey method with the key variables of health status and economic status. Quasi-experimental pre-post design with economic rebound as the intervention.

Setting-A relatively low income geographical area in a rural, mountainous region before and after an economic rebound. In 1990, the local economy and health care system collapsed because of the closure of a series of manufacturing plants; outward migration from the area peaked. Between 1990 and 1993, new industries opened, and state and private community assistance programmes intervened, resulting in an economic rebound, migration into the area, and marked growth of the health service sector.
\end{abstract}

Participants-A 2\% sample of residents of households, using a combination of random, stratified, and clustered sampling. Residents included in the study had lived within the area throughout the 1990-1993 period of the study.

Main results-Stable, non-migrating residents had a statistically significant $7 \%$ reduction in health status between 1990 and 1993, as measured by a composite of subjective and objective measures. The non-migrating residents also had a significant decrease in average household income (\$14 700 in 1990 and $\$ 12400$ in 1993 in constant 1990 dollars) during the strong economic expansion, and therefore did not participate in or receive direct economic benefit from the expansion. There was a rapid population increase during the expansion, attributable to inward migrants who were younger and healthier than existing residents. The decline in health for the non-migrating residents was tentatively attributed to either direct or indirect effects of the decline in family income.

Conclusions-Local economic development accompanied by expanded health care services availability can leave existing area residents poorer and less healthy, and this problem may be masked by an abundance of healthier, wealthier inward migrants.

(F Epidemiol Community Health 1998;52:749-757)
Although there have been many studies on the subject, a general consensus on the link between economy and health is lacking. Certainly, economic growth in industrialised countries in the past century has been associated with increased longevity and lower mortality, but the key factors could be increased knowledge in the biomedical sciences, improved public health programmes (such as vaccination programmes), or improved health promoting practices by an increasingly more educated public. ${ }^{12}$ Economic recessions and expansions in the past decades have been not always been associated with changes in population health in the anticipated direction, either in the industrialised countries $^{3-10}$ or in developing countries. ${ }^{11-16}$ The analysis is complicated in the United States by the geographical association of population density, and thereby economic activity, with health. That is, residents of rural areas have a lower age adjusted death rate than their urban counterparts. The lower probability of death in geographical areas of low economic activity is not limited to a few major diseases, but instead it is lower for all causes of death. ${ }^{17}{ }^{18}$

Few studies have focused on the health effects of local economic fluctuations of sufficient degree to cause changes in health services to a specific community. Bindman et $a l^{19}$ and Muus et $a l^{20}$ studied the health effects of a public hospital closure in a small community. Patients of the hospital completed a health assessment survey before the hospital closed and then completed another survey one year after the hospital closed. Bindman et $a l^{19}$ found a decline in self reported health status, which was attributed to hospital closure. Another study by Fihn and Wicher ${ }^{21}$ found that the withdrawal of medical services to indigent patients led to excessive mortality and hospital admissions, perhaps because of the absence of transportation and access to other clinic sites.

On the other hand, Krakauer et al ${ }^{2}$ studied the relation between density of health services and both morbidity and mortality in a national sample using a combination of federal databases. Although measures of local area economic activity were not incorporated into the study, neither the density of physicians, the density of hospitals, nor the medical specialty mix in a particular market area had any significant effect on mortality or morbidity. This implies that economic recessions and hospital closures have no effect on community health. 
The lack of consensus to date can be attributed to many potential factors because the studies have a great variety of approaches and have sampled populations with different characteristics. Another factor is that few had experimental or even quasi-experimental designs. Most were cross sectional in nature, comparing different populations in different places or different times. The problem with cross sectional approaches is that it can be difficult to extract the important links from among many mutually dependent and correlated economic and health measures. Consequently, this study was conducted using a longitudinal design in an effort to determine whether a geographically localised economic upturn in a relatively isolated, poor, rural region that led to major expansions in local health care services was accompanied by measurable increases in the health and well being of residents in the region.

\section{Methods}

SETTING

The sample frame was all residents in a geographical area called Johnson County, Tennessee (population about 14000 ), which is a mountainous region with no controlled access highways (interstate highways) and only one incorporated town within its borders (population 2169 in 1990). The county is designated by the US Government as $100 \%$ rural and as a Health Professions Shortage Area. The county was selected for the following reasons: (1) a high percentage of the population lived in poverty, (2) poverty was exacerbated by a local economic downturn, and (3) an economic downturn diminished health care services in the county. All areas of the county were within a two hour drive of the university based offices of the investigators and interviewers, which was important to the financial feasibility of conducting this study.

COHORT

A systematic sample of households was drawn from a listing of dwellings in the area according to seven different geographical divisions or strata. Every person 16 years of age or over was interviewed in each dwelling, and data on persons 15 years or younger was provided by proxy from an adult household member.

The interviews were repeated in both 1991 and 1993 at the same households sampled in 1990. The present report is based on a $2 \%$ sample of residents of the area that had the following characteristics: (1) over 18 years of age, (2) lived in the county (although not necessarily at the same address) in both the 1990 and 1993 survey. As described in the results section, the area had experienced some major changes in its economy during this time period, resulting in a relatively high level of emigration and immigration. The present cohort had remained in the county through this period, which enabled a pair-wise comparison of differences in the cohort over time without the complication of shifts in sample composition caused by immigration or emigration.
In 1990, interviews were attempted with 541 residents, of whom 15 refused, resulting in 526 interviews in 220 homes (97.2\% interview success rate). Another 16\% refused in 1991 and $38 \%$ in 1993 . Between 1990 (when the area was in the depths of a local economic recession) and 1993, 94 residents either positively migrated out of the county (and hence the sample frame) or were assumed to have migrated by the process of elimination because they were not found in typical sources (inquiries with neighbours or known relatives, telephone book, forwarding addresses with post office). This corresponds to an out of county migration rate of $6.0 \%$ per year, a rate close to the national average of $6.3 \%$ per year. ${ }^{23}$ In 1993, there were 354 successful interviews in 175 homes for a total loss of $32.6 \%$ of interviewed residents between 1990 and 1993. The 1993 only interview success rate was $85 \%$. Of these, 274 were over the age of 15 and consequently formed the sample for the study.

INSTRUMENTS

The survey used by the interviewers consisted of 48 items in 1990, 62 items in 1991, and 56 items in 1993. Five domains were covered in the following order: (1) health status and work limitations, (2) employment, (3) access to health care services, (4) perceptions of problems in the area, (5) demographic data. Items of basic significance were maintained through all three surveys (34\%), but items that provided highly skewed responses or a great number of missing responses in 1990 were modified $(50 \%)$ or dropped $(16 \%)$ in subsequent surveys. The 1991 and 1993 surveys were nearly identical, with $88 \%$ overlap between the items. All but two of the variables in the analysis came from the basic group of unmodified items.

Reliability and validity.

For convenience in analysis, a single, physical health factor score was devised by merging the available measures of physical health, and its reliability and validity was assessed. The motivation was to have a single score that combined both the subjective and objective measures of health, all of which were closely correlated, as discussed below. The self reported health status $(h)$, physical health score $(d)$ from the Duke Health Profile, ${ }^{24}$ and number of self reported medical conditions (c) were equally weighted and combined into the health factor score $(f)$ as follows:

$$
f=\frac{1}{3}\left(\frac{4-h}{3}+\frac{d}{100}+\left(1-\frac{\ln (c+1)}{\ln (4)}\right)\right)
$$

where $\ln$ is the natural logarithm. Variable $d$ varied from 0 to $100,{ }^{24} h$ varied from 1 (excellent) to 4 (poor), and $c$ varied from 0 to 3 (see Appendix). The health factor score $f$ varied from 0 (poor health) to 1 (excellent health).

By virtue of the fact that all three variables are related to a person's physical health, the health factor score has construct validity. Self reported health ${ }^{25}$ and the Duke Health Profile ${ }^{24}$ 


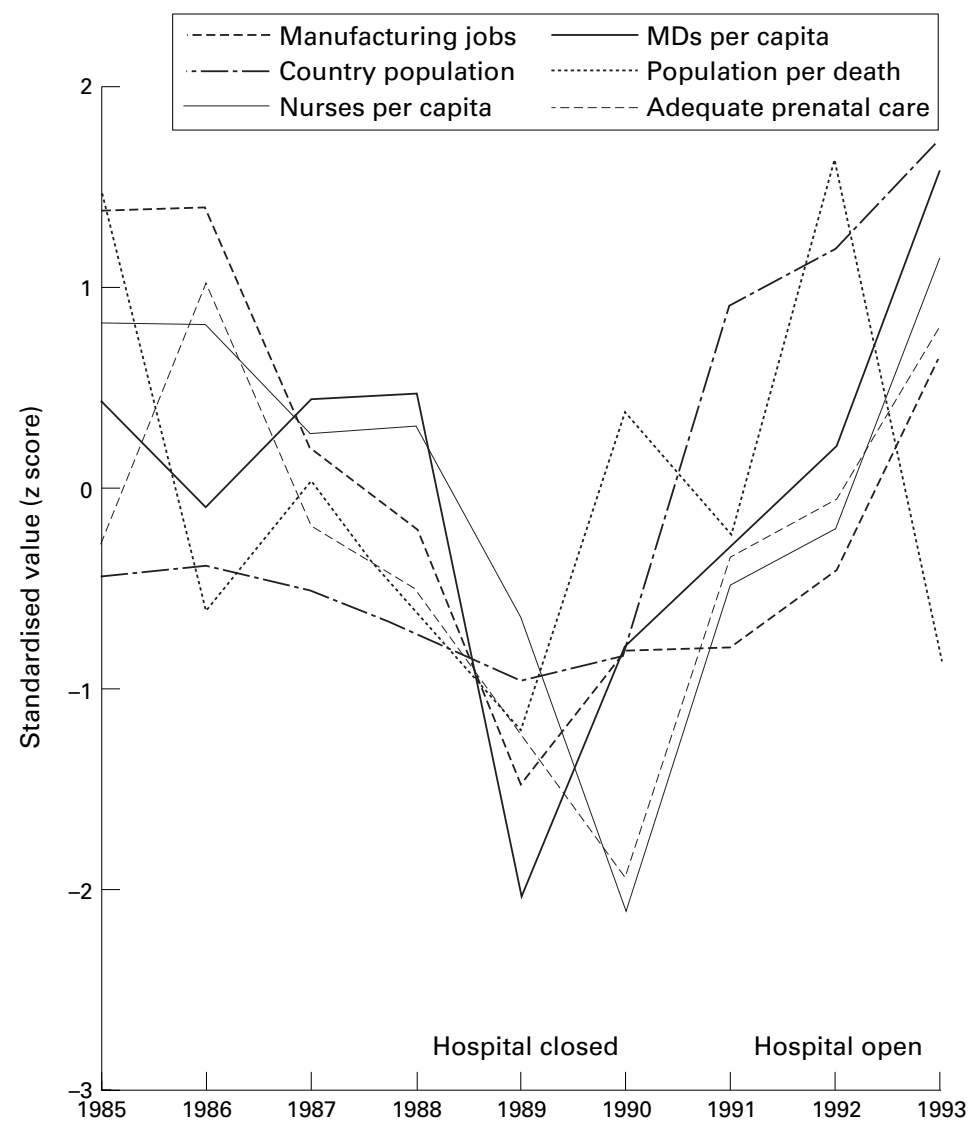

Figure 1 Summary of the economy, health service accessibility, and health indicators in the exact geographical area in which the study was conducted. Population per death is the inverse of death rate; and prenatal care reflects the percentage of births in which prenatal care was adequate, according to the Kessner Index. ${ }^{41}$ The years when the only area hospital closed and reopened are indicated. The mean is zero and the standard deviation is one for all six variables plotted because of standardisation. The unstandardised means and standard deviations are 1647 (125) (number of manufacturing jobs), 14373 (720) (total county population), 189 (44) per 100000 (nurses per capita), 41 (15) per 100000 (MD physicians per capita), 96.73 (11.49) (county population per death), and 92.6 (2.9) per 100 (births with adequate prenatal care).

have been shown to be valid predictors of future health. The internal validity was measured in two ways. Firstly, by the multiple correlation coefficient for the above three variables, which was $r^{2}=0.68$. Secondly, by the correlation of the original three variables to the health factor score: the correlation coefficients were 0.85 for $h, 0.88$ for $d$, and 0.87 for $c$. To reiterate a point made in a previous paragraph, the impetus for combining these variables into a single score was the above multicolinearity. Measurements of the external validity were not done in this study, but the external validity of the three items that comprise $f$ has been documented in relation to the external criteria of number of days in hospital per year and probability of death. ${ }^{24-26}$

The reliability of $f$ was $\alpha=0.91$, as measured using the repeated test split half method with the Spearman-Brown correction. The interviews of 1990 and 1991 served as the repeated tests, and the assumption implicit in the reliability test was that the health status of the subjects did not change in this interval. Of course, the health status of people does change over the course of a year, so even the relatively high reliability of 0.91 is just a lower bound.

\section{DATA ANALYSIS}

The investigators coded the open ended interview responses. The coded data were entered into computers separately for each year using the SPSS program, and subsequently all three years were merged into a single database in which all responses for a given subject were on the same row of the data matrix.

Cases were weighted during the statistical analysis to compensate for the clustered, stratified sample design. ${ }^{27}$ All weights were the sample selection type and were equal to the inverse of the probability of a case being selected for each cluster and stratum. The weights were relative weights, and had a mean of 1.0 and standard deviation of 0.32 .

The statistical analysis used a hierarchy of parametric and non-parametric, univariate and bivariate statistics, including the $t$ test, analysis of variance (one way and repeated measures), and Spearman or Pearson correlation coefficient. The particular test used depended on whether the variable was interval, ordinal, or nominal, and whether or not it had a unimodal distribution with tails on each side of the mode. Hypothesis testing was conducted using either the one tailed or two tailed version of the paired $t$ test, which is a relatively conservative approach, blindly in all comparisons in this study. The significance levels of the statistical hypothesis tests were adjusted for the number of comparisons by dividing the significance level for each test by the total number of separate hypotheses tested, which was counted as 14 (that is, $\mathrm{p}_{\text {adj }}=\mathrm{p}_{\text {raw }} / 14$ ). After adjustment, the level at which the null hypothesis was rejected was $p=0.05$. All $p$ values given in the text and tables are adjusted.

To provide the maximum information in table 1 in the simplest form possible, categorical variables are shown but statistical calculations of the $\mathrm{p}$ values were based on the underlying continuous or ordinal variable. Although it is unconventional to display categorical percentage next to $p$ values derived from an interval or ordinal hypothesis test, it is not erroneous or misleading because the two correspond closely or, under many circumstances, identically.

\section{Results}

OVERVIEW OF ECONOMY AND HEALTH SERVICES Recent data from the US Census Bureau (STF3c data file) show that the geographical area herein studied (called Johnson County) was in the depths of a locally severe recession in 1989 and 1990 (fig 1). The primary employers in the area were in the manufacturing sector, and there was a $20 \%$ reduction in the number of manufacturing jobs over five years. As jobs decreased, the total population began to drop because of an outward migration of displaced workers. The population in the geographical area had experienced a $10 \%$ growth rate in the previous decade but now declined by $3 \%$ over five years (see 1985 to 1990 in fig 1). After the closure of the largest manufacturing plant in the study area in 1989, the unemployment rate transiently surpassed $30 \%{ }^{27}$ 
Table 1 Interview responses of 274 adults during an economic recession (1990) and expansion (1993). The $p$ value comes from the paired t test using the continuous interval-grade counterpart of the variable in the table, and p has been adjusted for the number of comparisons made using the Bonferroni method. Interview items that gave rise to the data in this table are shown in the appendix

\begin{tabular}{|c|c|c|c|}
\hline \multirow[b]{2}{*}{ Item } & \multicolumn{2}{|c|}{ Percentage } & \multirow[b]{2}{*}{$p$ Value } \\
\hline & 1990 & 1993 & \\
\hline Unemployed in last two years $\dagger$ & 38.5 & 9.3 & * \\
\hline Annual income of less than $\$ 15000$ & 42.9 & 52.1 & \\
\hline Have health insurance & 88.5 & 89.0 & \\
\hline Five or more living in household & 11.0 & 2.8 & $\star \star$ \\
\hline Multigenerational or multifamily households & 16.6 & 9.4 & \\
\hline Single parent with children & 4.1 & 5.6 & \\
\hline Self reported health status is excellent & 20.2 & 12.5 & * \\
\hline Not worried about health at all & 41.6 & 32.2 & \\
\hline Two or more medical conditions & 16.0 & 25.7 & $\star \star$ \\
\hline Mental health score over 80 (Duke Health Profile) & 61.9 & 67.3 & \\
\hline Physical health score over 80 (Duke Health Profile) & 40.0 & 29.3 & $\star \star$ \\
\hline More than 3 visits to health care provider in 12 months & 41.4 & 40.2 & \\
\hline Kept from work by illness in past 12 months & 20.9 & 22.9 & \\
\hline Have a usual health care provider & 87.7 & 87.9 & \\
\hline
\end{tabular}

†1990 column refers to $1989-1991$ period 1993 column refers to $1992-1993$ period. ${ }^{\star} \mathrm{p}<0.05$, $\star \star \mathrm{k}<0.01$.

The number of health care providers also decreased markedly in correlation with the decline in the number of manufacturing jobs. At its lowest point in 1989, the only hospital in the county had closed, and there were only three generalist physicians in a county of over 13000 people. The reduction in health care providers was accompanied by decreases in measures of community health. That is, both the death rate and the number of births for which prenatal care was inadequate increased slightly (fig 1). After 1990, new manufacturing and government employment led to a relatively abrupt reversal of the negative trend. All indicators improved from 1990 to 1993, and the sole county hospital reopened. The connection between the economy and the geographical density of physicians was a reflection of the fact that the total number of medical doctors was more closely correlated with the number of employed persons in the study area than any other variable compared in the present study (Pearson's $r=0.86 \pm 0.6695 \%$ confidence intervals $(C I)$ for $1985-1993$ period; $n=9$ ).

DEMOGRAPHIC CHARACTERISTICS OF THE RESIDENTS

The average age of the 274 subjects was 53.0 (16.7 SD) with a range of 18 to 87 in 1990 . The gender proportion was $57.9 \%$ female and $42.1 \%$ male. The racial composition of the sample, like the area population, was almost entirely white $(99.5 \%)$. Twenty six per cent had never attended high school $(<10$ years of education), $35.1 \%$ per cent had graduated from high school (13 years of education), and $5.2 \%$ had graduated from a four year college programme ( $>17$ years of education). Seventy five per cent of residents were married (in both 1990 and 1993), and 18\% were divorced, separated, or widowed in 1990 , and $18 \%$ in 1993.

National government statistics (from US Census Bureau) indicate that $28.5 \%$ of in the study area residents were below the poverty line in 1990 . The poverty line changes annually and none of the items in this study permit an exact comparison to the US Census Bureau percentage; however, there is an approximate correspondence in that $24.1 \%$ of the residents reported incomes under $\$ 10000$ in 1990 and $42.9 \%$ reported incomes under $\$ 15000$.

The study area was comprised of a relatively low proportion of transient or migrating residents before 1990. Sixty one per cent of the 274 residents interviewed were born and raised in the county. Ninety two per cent had lived there 10 years or more, and only $3 \%$ had lived there three years or less. Sixty nine per cent had lived at their present address for 10 years or more and $13.1 \%$ had lived at their present address for three years or less. A large immigration flow that increased county population by $18 \%$ between 1990 and 1993 modified these figures significantly, as described next.

COMPARISON BETWEEN 1990 AND 1993 INTERVIEW RESPONSES

The interview responses of adults (defined as persons born before 1 January 1972) were compared in the years 1990 and 1993. These years were chosen because of all of the years in which we conducted the countywide household interview survey, 1990 and 1993 represented the worst and best years for the area, respectively (fig 1). In research terms, the study had a quasi-experimental pre-post design with the economic recovery comprising the intervention.

\section{Employment and income}

As table 1 shows, four times as many residents in the sample reported that they were unemployed in 1990 or 1991 than in 1992 or 1993 years. In 1993, $57.3 \%$ of residents said that life in the area had improved, $36.4 \%$ said it was the same, and $6.4 \%$ said it was worse. There was evidence that different families tended to live together and that households had a greater number of people during the local economic downturn. The average household size was $2.70 \pm 0.1695 \% \mathrm{CI}$ in 1990 as compared with $2.42 \pm 0.1295 \% \mathrm{CI}$ in $1993(\mathrm{n}=274)$. A greater proportion of the households was comprised of multiple unrelated families or multiple generation families (three or more generations, or two generations with extended family members) during the downturn. There were 53 such households in 1990, but only 41 in 1993. This was interpreted as a reflection of the reduced number of jobs in 1990, which caused economic hardship for many people, forcing them to move in with friends or relatives.

Paradoxically, the raw annual income per household was lower in 1993 than 1990, and the difference was statistically significant $(t=3.83, \mathrm{p}<0.0005)$. When adjusted for the effects of monetary inflation, the difference was even greater. The income was adjusted for an inflation rate of $3 \%$, which is a conservative figure because US official estimates (known as the consumer price index) showed annual increases that ranged from 3.0 to $5.4 \%$ in the 1990 to 1993 years. The average inflation adjusted income was estimated at $\$ 14700$ in 1990 and $\$ 12400$ in 1993 in constant 1990 dollars (using linear interpolation across income categories). This finding persisted after 
five new retirees were removed from the sample after restricting the sample to residents with household incomes under $\$ 15000$. It would thus appear that many of the residents who stayed in the area and weathered the local recession accepted lower wage jobs, and their wages were still low after the economic rebound was complete. An analysis of job types showed an increase in the number of service and managerial jobs (from 22 to 34 ) and a decrease in the number of professional jobs (from 23 to 10) in this sample, which supports this interpretation. If it is considered that the income per capita rose $8.7 \%$ in the county and the total county personal income rose $23.2 \%$ from 1990 to 1993 (US Census Bureau, 1996), then we must conclude that the new job openings during the recovery years would appear to have primarily gone to the large numbers of people who migrated into the county after 1990.

\section{Health status}

The physical health of the interviewed cohort dropped between 1990 and 1993 according to several separate measures. As table 1 shows, self reported health diminished, the number of medical problems reported increased, and the physical health score from Duke Health Profile decreased. Specifically, the difference in self reported health on a 4 point scale from excellent (1) to poor (4) was 2.33 (0.94 SD) in 1990 and $2.46(0.86)$ in 1993, which was statistically significant $(t=2.75, \quad \mathrm{p}<0.05$, $\mathrm{n}=274$ ). The physical health score on the Duke Health Profile ${ }^{24}$ on a 100 point scale from 0 (poor health) to 100 (excellent health) dropped from a mean of 62.4 (28.3 SD) to 58.1 (26.6 SD) $(t=3.31, \mathrm{p}<0.01, \mathrm{n}=268)$. Each subject was asked to list all medical conditions with which they were affiliated, such as arthritis, diabetes, heart problems, etc. The mean number of conditions increased from 0.63 (0.79 SD) per person in 1990 to 0.80 (1.10) per person in $1993(t=-3.02, \mathrm{p}<.05, \mathrm{n}=274)$. The number of visits to health care providers increased somewhat from 4.22 to 4.77 visits per year; however, the difference was not significant $(p>0.3)$. To sum up, several different self reported measures of health status seem to indicate that health had declined between 1990 and 1993 .

The decline in physical health indices was not apparently accompanied by increased depression or anxiety, however. In fact, the mental health score from the Duke Health Profile improved slightly, from 79.1 (19.1 SD) to 81.2 (19.3), but the difference was not significant $(t=-1.6, \mathrm{p}>0.3)$. This finding is in keeping with the positive outlook that residents had in 1993, as described above, where $57.3 \%$ of residents stated that life in the area had improved.

Given that the number of health problems increased between 1990 and 1993, we investigated the type of problems. Specifically, there were 48 more conditions reported across all interviewed residents in 1993 than 1990, and the identity of these conditions was sought. The 48 new conditions were varied in nature,
KEY POINTS

- Rapid economic expansion in a community led to a paradoxical decline in income and health among permanent residents.

- The health decline was accounted for by the income decline, but not by any other measured factors.

- The new jobs created during expansion appeared to either pay less or be filled by non-residents who subsequently migrated into the community.

- A concurrent expansion of health care services was not accompanied by reduced driving times or increased visits to health care providers.

with few cases of any particular type. In fact, the numbers within major disease categories became too small for any meaningful analysis. The top three conditions that increased in prevalence were arthritis (16 new cases), heart problems (10 new cases), visual or hearing problems (8 new cases). Expressed in terms of physiological systems, the top three were musculoskeletal system (21 new cases), nervous system (14 new cases), and cardiovascular system (12 new cases). There were also three new cases of diabetes, three new cases of other endocrine or immunological problems, and two new cases of stomach or digestive cancer. The sample sizes are too small for a definitive comparison, but the above distribution of diseases is comparable to the major causes of medical morbidity and impairment in industrialised nations, showing no unusual dominance of any particular disorder. This would be consistent with the notion that a very general risk factor, one related to a wide variety of disorders, increased during the 1990 to 1993 period. Examples of such risk factors are age, family income, education level, weight-height ratio, and many others.

EXPLAINING THE DECLINING HEALTH RATINGS It was not possible with the data to deduce the explanation for the apparent reduction in health between 1990 and 1993. It was possible to rule out a number of potential explanations, as follows.

Although the data were limited in this regard, there appeared to be a general increase across a broad spectrum of common disorders. A marked increase in the incidence of a particular disease was ruled out.

The possibility existed that the aging of the cohort by three years could explain the health reduction between 1990 and 1993. The health status variables were converted into a single health factor score, as described in the Methods section. The purpose was to have a single dependent variable that represented physical health rather than the three highly correlated dependent variables, for simplicity in the further analyses. The average health factor score was 0.643 in 1990 and 0.602 in 1993 , for a $7 \%$ reduction in three years. Figure 2 shows the decline in the health factor score with age. Note that with the exception of the 


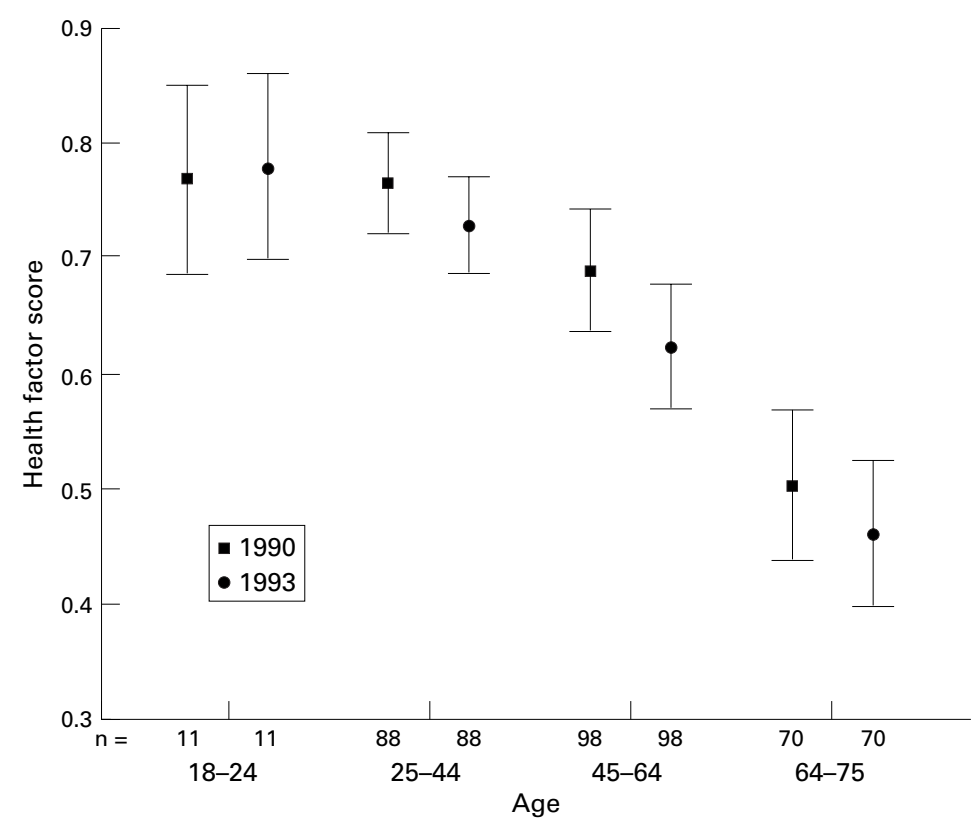

Figure 2 Changes in a physical health scores between 1990 and 1993 according to age group (mean (SEM)). Maximum health score possible is 1 and minimum possible is 0.

Number of interviewed residents in each age group $(n)$ is shown below horizontal axis.

youngest age group, all groups show an age dependent decline in the health score. The three year decline is, however, far in excess of that expected by age alone. This was quantified by a repeated measures analysis of variance in which the health score in different years was the within subjects effect and the age group was the between subjects effect. The 1990-1993 difference had a $\eta^{2}$ of 0.015 and age group had a $\eta^{2}$ of 0.178 . The $\eta$ ratio is the square root of $0.015 / 0.178$ or $29 \%$. That is, the three year reduction in health was roughly equivalent of one third of an adult life span of about 55 years (that is, 73-18), not just a three year period. Therefore, we conclude that only about one sixth ( 3 years $\div 29 \% \times 55$ years) of the reduction in health between 1990 and 1993 is caused by effects of aging three years.

To check on the possibility that the 1993 health reduction was a statistical aberration, data from a 1991 cohort interview were analysed to see if there was any sign of a gradual reduction in health. Data on the health status of the present cohort was collected in 1991 , but not in 1992. The combined health factor score was 0.643 (0.276 SD) in 1990, $0.631(0.283)$ in 1991 , and $0.602(0.270)$ in 1993. In fact, all three health measures that are used to compute the health factor score (self rated health, physical health from the Duke Health Profile, and number of conditions) had values in 1991 that were intermediate between 1990 and 1993. The incremental reductions in health score are consequently unlikely to be a statistical aberration.

Several other possible explanations were ruled out. Differences in the order of the interview items in 1990 and 1993 could hypothetically explain the health decline. This was ruled out because the self rated health item is one of the first items posed in the interview in both surveys, and as noted above, it declined. The possibility was tested that it could be explained by differences in the particular month that the subjects were interviewed in 1990 and 1993. A one way analysis of variance was conducted using self rated health as the independent variable and the month of the interview as the dependent variable. The effect of the month of interview was not significant, nor was there a trend towards significance $(F=1.04, \mathrm{p}>0.4)$.

The last possibility tested was that the health decline was related in some way to income or workload. The Spearman non-parametric correlation was calculated for the relation between number of jobs worked simultaneously at the time of the interview and health factor score (limited to the subsample of workers in the age range of 18 to 65 ).

In a cross sectional analysis of 1990 data, the number of jobs worked had no discernible effect on health factor score $(r=-0.071,95 \% \mathrm{CI}$ $= \pm 0.13)$. Health did, however, vary with income $(r=0.30,95 \% \mathrm{CI}= \pm 0.13)$. Variations in occupational workload were thus ruled out. Tenable explanations that could not be ruled out by these data will be discussed in the following section.

\section{Discussion}

A period of recovery from economic distress in the rural community under study was paralleled by growth in the medical service sector. Two paradoxical findings resulted: (1) Self reported health status of residents was significantly lower after the economic recovery. (2) Despite the marked economic improvement as reflected in official government statistics, the income of the non-migrating residents went down, even after excluding new retirees from the cohort. These findings will be discussed separately.

DECLINE IN HEALTH STATUS MEASUREMENT With regard to the health reduction, several possible explanations were ruled out in the results section. The reduction was not found to because of: (1) the normal effects of aging, (2) a statistical aberration that deviated from some other time trend, (3) chance selection of an uncharacteristic sample of county residents, (4) differences in the order of interview items, (5) seasonal differences in health, or (6) increased or decreased occupational workloads.

Explanations that were not ruled out and remain plausible include: (1) The expansion of health services and community health screenings increased individual awareness of the existence of any personal medical problems, ${ }^{28}$ and (2) Health decline was real and caused by a paradoxical decline in family income during the economic rebound. Weak evidence was found that supported the second possibility as the more likely of the two. The most common year in which the resident's main limiting health condition was first noticed was in 1986 or 1988 and not 1992 or 1993 . Moreover, there was no increase in the number of residents with health conditions that were first noticed in 1992 or 1993. Neither of these are fully consistent with the first explanation. On the 
other hand, other studies have shown that health access can indeed affect health services utilisation and self rated health. ${ }^{28} 29$

With regard to the second possible explanation, evidence for contribution of income decline to the health decline was found in the form of a concurrence in a longitudinal analysis (table 1) and an association in a cross sectional analysis (see Results section). Moreover, personal income is among the most well established of known risk factors for poor health, affecting a broad spectrum of disorders. ${ }^{30-36}$ This is consistent with the finding (see Results) that there was an increase in the prevalence of a broad range of common disorders.

The explanation for the income-health connection is a major puzzle in epidemiology and community health. A minimum level of health is clearly required to produce an income. ${ }^{37}$ However, this is not the full explanation. Ettner ${ }^{38}$ used a two stage probit analysis on US survey data to adjust for the main effect of health on income level, and found statistical evidence for a strong reverse effect of income on health. A full treatise of this problem is beyond the scope of this study, but the following statement can be made: The bulk of the evidence from this and other studies best support the explanation that the health decline over a three year local economic expansion was a consequence of an income reduction in the non-migrating residents.

The ensuing question was posed of how real income could decrease during a strong economic rebound. The answer is that the bulk of new employment in the county went to workers that relocated from other areas. According to government statistics on the geographical area studied (US Census files CB96-32 Rel. 3/8/96), the population increased from 13766 residents in 1990 to 15235 residents in 1993. The population under 65 years of age increased $12.2 \%$ (from 11512 to 12960 ) over this period, but the population over 65 years of age increased only $3.3 \%$ (from 2254 to 2329). Consequently, the inward migrants tended to be younger and healthier than existing residents, and appear to be the main beneficiaries of the economic growth.

The next part of the discussion concerns the general question of whether there is a link between the economic status of the health services sector and population health generally. As important as this issue is, there are few studies that squarely evaluate health service economics and health. One of these studies is that of Krakauer et $a l^{22}$ who studied the relation of the geographical density of health services to morbidity and mortality in 1.9 million patients across 803 health care market areas across the nation. Neither the density of physicians, the density of hospitals, nor the medical specialty mix in a particular market area had any significant effect on mortality or morbidity. These findings and others, ${ }^{29}$ although not decisive, contrast markedly with the worries that communities have when local hospitals close. ${ }^{20}$
The findings in this study are the opposite of those of Bindman et al. ${ }^{19}$ The foregoing investigators found the health of hospital users in a rural community to diminish after the hospital closed. The number of patients who reported that they had no regular health care provider increased from $14 \%$ to $28 \%$ one year after the closure; whereas in the present study, however, there was no difference after hospital reopening. Bindman et $a l^{19}$ found a statistically significant decline in self reported health status (at $\mathrm{p}<0.05$ ) after hospital closure, whereas we found a significant, paradoxical decline after hospital reopening.

There are many differences between the two studies that could account for the discrepancy. Bindman et $a l^{19}$ studied the effect of hospital closure in 1988 on former inpatients; whereas we studied the effect of hospital reopening in 1992 on a sample of all residents. In an attempt to make our study more comparable to that of Bindman et $a l,{ }^{19}$ we conducted a separate post hoc analysis of the health status of a subsample who had been inpatients (in one or more of the past five years) and found little difference in health decline as compared with the full sample (decline of 0.051 in $F$ for 148 inpatients compared with decline of 0.063 for 138 noninpatients). This contrasts with the findings of Bindman et al. ${ }^{19}$ It is possible the health reduction upon hospital closure in their sample of inpatients was actually because of income decline and not hospital closure, regardless of whether the local economy was expanding or receding. This possibility receives further support when the wider question is considered of whether or not economic upturns and downturns have a measurable effect on population health.

Previous studies on the relation between health and economic growth have been mixed. Brenner $^{3}$ and Bunn ${ }^{4}$ reported that periods of recession were accompanied by increases in heart disease and stroke. However, these findings were not replicated in other studies. ${ }^{56}$ Trent $^{8}$ found evidence in government data of diminished mental health and well being during a recession, as did Catalano. ${ }^{7}$ The two latter authors differed in that Catalano ${ }^{7}$ found weaker evidence for increased suicide, neonatal deaths, or heart disease. As far as morbidity is concerned, Aronoff ${ }^{9}$ pointed out that disability epidemics are the rule during economic recessions, but that they are caused not only by objective impairment but also by diminished job satisfaction and financial security. Miller et $a l^{10}$ noted that the health of children has not declined in recent US recessions, and attributed this to protection by expanded health and social services. In regions with small industrial economies, economic recessions and recoveries have been associated with outbreaks of disease, ${ }^{11} 3940$ whereas economic development has been associated with improved nutrition and life expectancy. ${ }^{12}$ Sanders and Davies, ${ }^{13}$ Brinkmann, ${ }^{14}$ and Finau, ${ }^{15}$ Alzaid et $a l^{16}$ found instances where economic growth had mixed or detrimental effects on community health, similar to the present study. Taken together, these studies show that economic growth is 
generally, but not always, associated with increases in population health. Mitigating factors often neutralise or reverse the economyhealth relation. The fact that some studies have previously found inverse relations between economy and community health provides an indirect validation of the present findings.

\section{LIMITATIONS}

Before drawing the final conclusion from this analysis, limitations to our findings need to be presented. This study is based completely on data reported by interviewed residents, and of course, people do not always answer factually in interview surveys. The key dependent variable in this study (health status) was shown to be valid (see Methods); however other more sensitive or controversial variables may be less valid, such as self report income or coverage by health insurance. On the other hand, the agreement between the US Census data and the present income averages, argues in favour of at least a moderate validity. When reviewing the data and findings of this study, the possibility that residents may unintentionally provide erroneous information needs to be considered.

This study was a case study in one type of rural area. The findings can accordingly only be extrapolated directly to areas with similar demographic, economic, and geographical characteristics. Although such areas are not great in number, they hold populations that have the lowest income, employment opportunities, and health care options in the US and in other countries. Whether or not the findings apply globally to residents who stay put during economic recessions remains to be determined.

\section{Conclusions}

When our findings and those of the other investigators discussed above are considered together with the different strengths and weaknesses of the differing data, we settle on the following general conclusions: Economic recoveries sufficient in size to lead to marked expansions in local health services can be accompanied by decrements in the health of residents. Economic development may only be beneficial to new residents who migrate into an area during or after the economic rebound.

The authors wish to acknowledge the valued contributions of Niles Schoening, Wayne Dunn, Caroline Reed Jijon, Dr Pamela Zahorik, Dr Joy Wachs, Dr Joellen Edwards, Dr Cynthia Lenz, Dr David Doane, Dr Paul Stanton, and all members of the Kellogg Community Partnerships Program.

\section{Appendix}

The list below shows the items from which variables included in table 1 were taken.

How many people live in your household?

Compared to the other people your age, would you say your own health is excellent, good, fair, or poor?

Excellent (1); Good (2); Fair (3); Poor (4)

Thinking back over the past 12 months, that is, since (MONTH) 1989, were you ever kept from going to work, school, (your usual activity) for at least two days in a row, because you had an illness or accident? Take your time if you need to think about this.

Yes (1); No (2)

How many different times in the past month were you kept from (usual activity) for at least two days in a row because of an illness or accident?

Do you have a medical doctor that you usually see for your health care?

Yes (1); No (2)

How many times have you been to see a medical doctor-any doctor-in the past 12 months - that is since (today's date)?

If currently unemployed, retired, or having work disability:

How long have you been unemployed (retired, disabled and unable to work)?

years months

Do you have any kind of health insurance?

No (1); Yes (2)

If "Yes," what kind of health insurance do you have?

Medicare (1); Medicaid (2); BCross/BShield (3); Other private insurance (4)

If "No" How long have you been without health insurance?

years months

Considering all the people that live in your household, and all the sources of income they might have, would you say the total household income for the past 12 months is less than $\$ 20000$ or more than $\$ 20000$ ?

Less than $\$ 20000$ (show card A); More than $\$ 20000$ (show card)

Now could you tell me which letter on this card best indicates your total household income for the past 12 months? (Show card)

What is your marital status? Are you:

Single (never married) (1); Married (2); Separated (3); Divorced (4); Widowed (5)

1 McKeown T, Record RG, Turner RD. An interpretation of the decline in mortality in England and Wales during the twentieth century. Population Studies 1975;29:391-422.

2 McKinlay JB, McKinlay SM. Medical measures and the decline of mortality. In: Conrad P, Kern R, eds. The sociology of health and illness: critical perspectives. 2 nd ed. New York: St Martin's Press, 1986:10-23.

3 Brenner MH. Relation of economic change to Swedish health and social well-being, 1950-1980. Soc Sci Med 1987;25:183-95

4 Bunn A. Ischaemic heart disease mortality and the business cycle in Australia. Am f Public Health 1979;69:772-81.

5 Cohen L, Felson M. On estimating the social costs of national economic policy: a critical examination of the Brenner study. Social Indicators Research 1979;6:251-9.

6 Forbes J, McGregor A. Male unemployment and causespecific mortality in postwar Scotland. Int $\mathcal{F}$ Health Serv specific mortality

7 Catalano R. The health effects of economic insecurity. $A m \mathcal{F}$ Public Health 1991;81:1148-52.

8 Trent B. Recession has taken more than an economic toll, physicians report. Can Med Assoc F 1992;147:741-4.

Aronoff GM. Chronic pain and the disability epidemic. Clin $f$ Pain 1991;7:330-8

10 Miller CA, Coulter EJ, Fine A, et al. 1984 update on the world economic crisis and the children: a United States case study. Int f Health Serv 1985;15:431-50.

11 Efem SE. Breast abscesses in Nigeria: lactational versus non-lactational. F R Coll Surg Edinb 1995;40:25-7.

12 Florentino RF, Pedro RA. Nutrition and socio-economic development in Southeast Asia. Proc Nutr Soc 1992;51:93104.

13 Sanders D, Davies R. The economy, the health sector and child health in Zimbabwe since independence. Soc Sci Med 1988;27:723-31. 
14 Brinkmann UK. Economic development and tropical disease. Ann N Y Acad Sci 1994;740:303-11.

15 Finau SA Development and health in the Pacific: which way to die. $P$ N G Med 7 1993;36:324-36.

16 Alzaid AA, Sobki S, De-Silva V Prevalence of microalbuminuria in Saudi Arabians with non-insulin-dependent diabetes mellitus: a clinic-based study. Diabetes Res Clin Pract 1994;26:115-20.

17 Schneider D, Greenburg MR. Death rates in rural North America. In: Gesler WM, Ricketts TC, eds. Health in rural North America. New Brunswick, NJ: Rutgers University Press, 1992:55-68.

18 Smith MH, Anderson RT, Bradham DD, et al. Rural and urban differences in mortality among Americans 55 years and older: Analysis of the National Longitudinal Mortality Study. F Rural Health 1995;11:274-85.

19 Bindman AB, Kean D, Lurie N. A public hospital closes. Impact on patients' access to care and health status. $\mathscr{f} A M A$ Impact on patients' acce

20 Muus KJ, Ludtke RL, Gibbens B. Community perceptions of rural hospital closure. $\mathcal{F}$ Community Health 1995;20:6573 .

21 Fihn SD, Wicher JB. Withdrawing routine outpatient medical services: effects on access and health. $\mathcal{F}$ Gen Intern Med 1988;3:356-62.

22 Krakauer H, Jacoby I, Millman M, et al. Physician impact on hospital admission and mortality rates in the Medicare population. Health Serv Res 1996;31:191.

23 US Census Bureau. Geographic mobility: March 1993 to March 1994. US Census Bureau. Report P20-485. Washington, DC: Government Printing Office, 1996:150.

24 Parkerson G, Broadhead WE, Chiu-Kit T. The Duke Health Profile: a 17-item measure of health and dysfunction. Med Care 1990:28:1056-72.

25 Gold M, Franks P, Erickson P. Assessing the health of the nation. The predictive validity of a preference-based measure and self-rated health. Med Care 1996;34:163-77.

26 Glenn LL, Jijon C. Risk-adjusted in-hospital death rates for peer hospitals in rural and urban regions. F Rural Health (In press).

27 Beck RW gender, perceived financial barriers to care, and health status in rural population. $\mathcal{F}$ Rural Health 1996;12:188.
28 Pampalon $\mathrm{R}$. The demand for health services: a geographic analysis in Quebec. Cah Sociol Demogr Med 1990;30:253-67.

29 Blazer DG, Landerman LR, Fillenbaum G, et al. Health services access and use among older adults in North Carolina: urban vs rural residents. Am $\mathcal{f}$ Public Health 1995;85:1384-90.

30 Edwards JB, Shuman P, Glenn LL. Relationships among health risk factors and objective physical findings in well family and Community 1996;18:67-80.

31 Bianchetti A, Rozzini R, Carabellese C, et al. Nutritional intake, socioeconomic conditions, and health status in a large elderly population. I Am Geriatr Soc 1990;38:521-6.

32 Mustard CA, Frohlich N. Socioeconomic status and the health of the population. Med Care 1995; (suppl):DS43-54.

33 Charlton BG, White M. Living on the margin: a salutogenic model for socio-economic differentials in health. Public Health 1995;109:235-43.

34 Winkleby MA, Jatulis DE, Frank E, et al. Socioeconomic status and health: how education, income, and occupation contribute to risk factors for cardiovascular disease. $A m \mathcal{F}$ Public Health 1992;82:816-20.

$35 \mathrm{Ng}$ E, Wilkins R. Maternal demographic characteristics and rates of low birth weight in Canada, 1961 to 1990 . Health Rep 1994;6:241-52.

36 Bergenudd $\mathrm{H}$, Nilsson B. The prevalence of locomotor complaints in middle age and their relationship to health and socioeconomic factors. Clin Orthop 1994; Nov: 264-70.

37 Desai S. The estimation of the health production function for low-income working men. Med Care 1987;25:604-15.

38 Ettner SL. New evidence on the relationship between income and health. F Health Econ 1996;15:67-85.

39 Roman GC. On politics and health: an epidemic of neurologic disease in Cuba. Ann Intern Med 1995;122:5303.

40 Adewuyi JO. Current prevalence and some clinical associations of childhood anaemia in urban and rural communities of central Nigeria. Cent Afr f Med 1992;38:66-72.

41 Kotelchuck M. An evaluation of the Kessner Adequacy of Prenatal Care Index and a proposed Adequacy of Prenatal Care Utilization Index. Am f Public Health 1994;84:1414-20 